\title{
Deaf-Mute Students Physical Health Development Strategy Research in the Perspective of Education Fair Equalization
}

\author{
Xiangyang Zhang and Shaohua $\mathrm{Yu}^{*}$
}

Liaoning University, Shenyang, Liaoning, China

\begin{abstract}
Focus on disabled people health, improve the disabled social position is another slogan that China has put forward in disabled people work aspects in recent years. As social vulnerable groups, deaf-mute students have attracted more and more attentions in recent years, their physical health becomes more and more important for deaf-mute students education. The paper is established in deaf-mute students' body basic quality, physical health standards and deaf-mute students' physical exercises hobbies, makes concrete analysis of them. Firstly, utilize normality test and discriminant analysis methods to research deaf-mute students' physical test completion all kinds of indicators, and then define their physical health standards. Secondly, on this basis, utilizes numerical analysis method, it analyzes deaf-mute students' physical exercises likability and gender differences, and finally gets conclusions: when carrying out sports test, it should consider deaf-mute students physique and normal students differences, and combine with different genders deaf-mute students' physical quality, formulate different physical health standards. In physical exercises two aspects, deaf-mute students' enthusiasm is obviously lower than normal students, and schoolgirl's preference extent on physical exercises is lower.
\end{abstract}

Keywords: Deaf-mute students, discriminant analysis, gender difference, normality test, physical health, vulnerable groups.

\section{INTRODUCTION}

In recent years, disabled people group has attracted more attentions from people in all walks of life, and it has already founded all kinds of organizations to help disabled people group to live, disabled persons foundation, disabled persons psychological counseling room, Paralympic Games and others, all are by far caring disabled people series activities of the biggest concerns [1].

Cheng Ming-Ji and others in the article "Deaf-mute people physical test indicators criterion correlation degree research" took deaf-mute people physical monitoring indicators as main research directions, researched on every indicator and its correlation degree sizes [2]. The paper by statistical disabled people physical test every item data, made comparative analysis with normal people indicators, utilized correlation degree method to analyze data features, and finally got conclusions. The paper pointed out: Deaf-mute people physical monitoring all kinds of indicators were obviously different from normal people, all kinds of indicators and deaf-mute people physical health were closely linked, the correlation degree sizes and normal people also had significant differences, when analyzing deaf-mute people physique, it should fully consider deaf-mute people physique [3].

Wang Ming-Yuan in the article "Hearing disabled students' physical health test surrogate markers research", took hearing disabled students as main research objects, in the perspective of hearing disabled students, researched on disabled students' physical health test surrogate markers. The paper referenced formers research results, combined with its own research orientations, got conclusions: in hearing disabled students' physical health test indicators, many indicators could be replaced as other changes significant indicators, as the item of physical health, it could be replaced into height, weight, lung capacity, heart rate and so on, so that more concrete and intuitional researched hearing disabled students' physical health, and meanwhile it also provided orientations for disabled students' physical health research [4].

$\mathrm{Lu} \mathrm{Xiu-Yun} \mathrm{in} \mathrm{the} \mathrm{article} \mathrm{"Shanghai} \mathrm{city} \mathrm{adolescent}$ physical health monitoring management mode exploratory study", took Shanghai city adolescent as an example, researched on his physical health monitoring management mode [5]. The paper summarized formers research results, and carried out exploratory research on adolescent monitoring management mode. The paper pointed out that adolescent physical health detection was very important for adolescent sound growth, its management should break through traditional mode, base on practical status, innovate management mode [6].

The paper utilizes mathematical methods, in the perspective of sports activities, makes quantitative analysis of deafmute students' physical health, researches from multiple perspectives, defines deaf-mute people physical health standards to provide orientations and theoretical base for China deaf-mute people group physical health research.

\section{NORMALITY TEST-BASED DEAF-MUTE STU- DENTS' PHYSICAL BASIC QUALITY}

According to disabled classification standards, it can divide disabled students into following types: vision 
disability, the hearing disability, speech disability, physical disabilities. In general, disabled students' physical quality and health students also have great differences, therefore when implementing all aspects activities; it should consider their physical quality (Fig. 1).

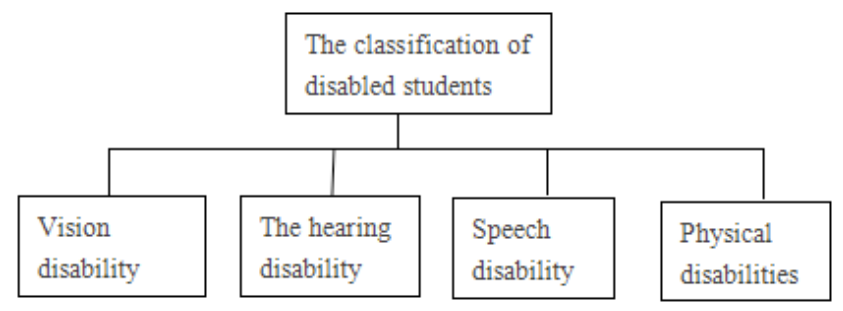

Fig. (1). The classification of disabled students.

Above Fig. (1) is disabled students' classification, from which according to different parts disabled extents, it divides into four main kinds. Now by statistical analysis, numerical analysis and discriminant analysis method, make researches on deaf-mute type students physical health standards so that provide theoretical basis for deaf-mute students education works.

\subsection{Normality Test Thought}

Normality test is firstly through hypothesis test calculation, and then generating normal probability graph, and then observing test value conforms to normal distribution or not. Normality test hypothesis is $H_{0}$ : data conforms to normal distribution, $H_{1}$ : Data doesn't conform to normal distribution.

Hypothesis testing: It is making statistics of inferred another type of important problems. In case that overall distribution function is unknown or only know its forms but don't know its parameters, to infer its overall some features, and then put forward one hypothesis.

Single totality $N\left(\mu, \sigma^{2}\right)$ average value $\mu$ testing:

Bilateral testing: $H_{0}: \mu=\mu_{0}, H_{1}: \mu \neq \mu_{0}$;

Right testing: $H_{0}: \mu \leq \mu_{0}, H_{1}: \mu>\mu_{0}$;

Left testing: $H_{0}: \mu \geq \mu_{0}, H_{1}: \mu<\mu_{0}$

Distribution fit testing:

When it cannot foresee totality conforms which kinds of distribution, it needs to test distribution hypothesis according to samples. Among them, it includes: $\chi^{2}$ test method: $H_{0}$ : Totality $x$ distribution function is $F(x)$,

$H_{1}$ : Totality $x$ distribution function is not $F(x)$

Its basic thought is:

It may divide totality $\Omega$ into $k$ pieces of incompatible events:

$$
A_{1}, A_{2}, A_{3}, \cdots, A_{k},\left(\sum_{i=1}^{k} A_{k}=\Omega, i \neq j, 1,2,3, \cdots, k\right)
$$

Then in hypothesis $H_{0}$, it can calculate $p_{i}=P\left(A_{i}\right)\left(\right.$ or $\left.\hat{p}_{i}=\hat{P}\left(A_{i}\right)\right), i=1,2, \cdots, k$. In $\mathrm{n}$ times of experiments, event $A_{i}$ occurrence frequency $f_{i} / n$ and $p_{i}\left(\hat{p}_{i}\right)$ have certain differences. But if $H_{0}$ is true, when experiments times are quite a lot, such differences will not be very big. For:

$$
\chi^{2}=\sum_{i=1}^{k} \frac{\left(f_{i}-n p_{i}\right)^{2}}{n p_{i}}\left(\text { or } \chi^{2}=\sum_{i=1}^{k} \frac{\left(f_{i}-n p_{i}^{\wedge}\right)^{2}}{n p^{\wedge}{ }_{i}}\right.
$$

As hypothesis testing statistical quantity, it proves following theorem:

If $n$ is big enough, then when $H_{0}$ is true, above statistical quantity always approximately conforms to freedom degree as $k-r-1 \chi^{2}$ distribution, from which $r$ is number of estimated parameters.

Then on the condition of hypothesis $H_{0}$, it can get: $\chi^{2} \geq \chi_{\alpha}^{2}(k-r-1)$

Then in significant level $\alpha$, refuse $H_{0}$, otherwise accept it.

\subsection{Data Integration}

By deaf-mute students' physical quality every aspect acknowledge, consult relative information, and combine with a great deal of research results, voluntarily draw following about deaf-mute students' physical monitoring data Table $\mathbf{1}$.

By above process, analyze Table 1 data, it can get following result Tables $\mathbf{2}$ and $\mathbf{3}$.

Make comparison of schoolboys and schoolgirls average value $X$, it can get following Fig. (2).

Table 1. Deaf-mute students' physical test completion all kinds of indicators.

\begin{tabular}{|c|c|c|c|c|c|c|c|c|c|c|}
\hline & Height & Weight & $\begin{array}{c}\text { Lung } \\
\text { Capacity }\end{array}$ & Step Test & $\begin{array}{c}\text { Sit and } \\
\text { Reach }\end{array}$ & Grip & $\begin{array}{c}\text { Vertical } \\
\text { Jump }\end{array}$ & $\begin{array}{c}\text { Push-up } \\
\text { (Men) }\end{array}$ & $\begin{array}{c}\text { Sit-up } \\
\text { (Women) }\end{array}$ & $\begin{array}{c}\text { Closed } \\
\text { One Leg } \\
\text { Standing }\end{array}$ \\
$\begin{array}{c}\text { Selection } \\
\text { Reaction } \\
\text { Time }\end{array}$ \\
\hline \hline $\begin{array}{c}\text { Completion } \\
\text { rate\% }\end{array}$ & 100 & 100 & 100 & 87.5 & 90 & 97.5 & 85 & 85 & 95 & 100 \\
\hline
\end{tabular}


Table 2. Test result (Men).

\begin{tabular}{|c|c|c|c|c|c|c|c|c|c|}
\hline & Height & Weight & $\begin{array}{c}\text { Lung } \\
\text { Capacity }\end{array}$ & Sit and Reach & Grip & $\begin{array}{c}\text { Standing } \\
\text { Long Jump }\end{array}$ & Push-up & $\begin{array}{c}\text { Selection } \\
\text { Reaction Time }\end{array}$ & $\begin{array}{c}\text { Closed One } \\
\text { Leg Standing }\end{array}$ \\
\hline \hline X- & 167.7 & 60.4 & 2548.0 & 8.72 & 41.5 & 200.0 & 12.2 & 0.576 & 14.5 \\
\hline S & 7.62 & 5.93 & 631.1 & 4.32 & 9.15 & 17.45 & 2.14 & 0.082 & 5.76 \\
\hline D & 0.27 & 0.27 & 0.276 & 0.28 & 0.26 & 0.277 & 0.274 & 0.273 & 0.277 \\
\hline
\end{tabular}

Table 3. Test result (women).

\begin{tabular}{|c|c|c|c|c|c|c|c|c|c|}
\hline & Height & Weight & $\begin{array}{c}\text { Lung } \\
\text { Capacity }\end{array}$ & Sit and Reach & Grip & $\begin{array}{l}\text { Standing } \\
\text { Long Jump }\end{array}$ & 1min Sit-up & $\begin{array}{l}\text { Selection Re- } \\
\text { action Time }\end{array}$ & $\begin{array}{l}\text { Closed One } \\
\text { Leg Standing }\end{array}$ \\
\hline$X-$ & 155.1 & 53.8 & 1795.4 & 8.96 & 25.5 & 163.2 & 17.6 & 0.532 & 9.2 \\
\hline $\mathrm{S}$ & 6.25 & 5.39 & 450.07 & 4.27 & 6.94 & 14.39 & 9.84 & 0.074 & 4.54 \\
\hline $\mathrm{D}$ & 0.275 & 0.28 & 0.277 & 0.27 & 0.26 & 0.277 & 0.275 & 0.274 & 0.276 \\
\hline
\end{tabular}

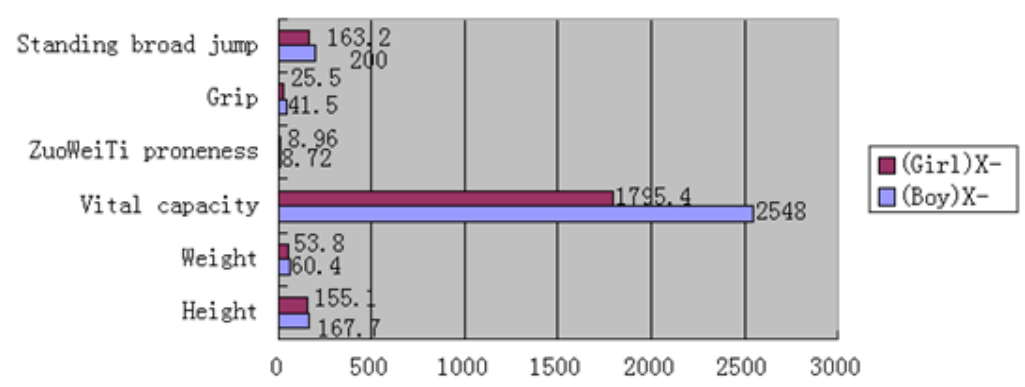

Fig. (2). The comparison of different gender X.

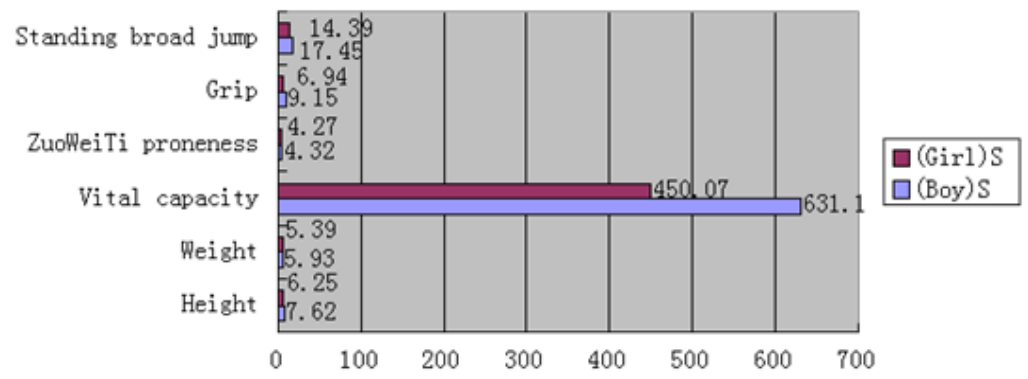

Fig. (3). The comparison of different gender S.

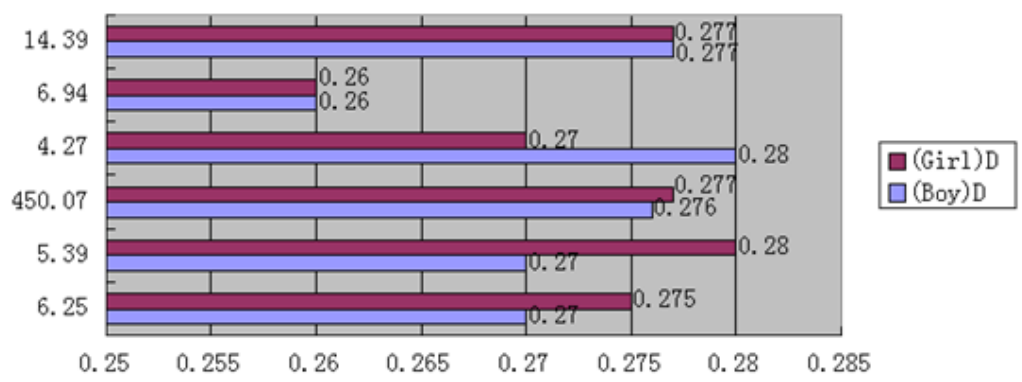

Fig. (4). The comparison of different gender D.

Make comparison of schoolboys and schoolgirls average value $S$, it can get following Fig. (3).

Make comparison of schoolboys and schoolgirls average value $D$, it can get following Fig. (4).
From above statistical test result, it can get conclusions: for deaf-mute students, their physiques have great differences. When doing lung capacity, sit and reach, grip and other physical testing, their performances have obvious differences. Therefore, when formulating physical criterions, 


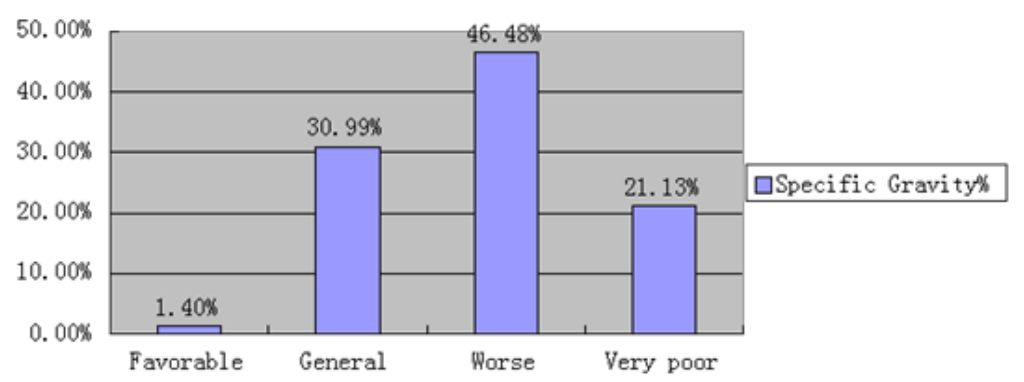

Fig. (5). The deaf students' ability to adapt to the society.

it also should according to their physiques differences, and respective regulate.

\section{DISCRIMINANT ANALYSIS METHOD-BASED DEAF-MUTE STUDENTS' PHYSICAL HEALTH STANDARDS RESEARCH}

Deaf-mute people are vulnerable group in society, their social positions often lower than normal ones, and are often ridiculed by many people, even suffer discrimination. Due to deaf-mute people physical defects, their social adaptabilities are also different. Below Fig. (5) is Chinese deaf-mute students' social adaptabilities extents reflection.

By above statistical figure, it is clear that deaf-mute students with good social adaptabilities are only small parts of group, most part of deaf-mute students and social adaptabilities are very bad. Therefore, research on deaf-mute students' physical health, and then make contributions to promote their social adaptabilities.

\subsection{Guiding Thought}

Discriminant analysis is a kind of multiple statistical analysis method; it refers to observe on known evaluation indicators and according to observed data to make classification on evaluation objects. Discriminant analysis general steps are as following Fig. (6).

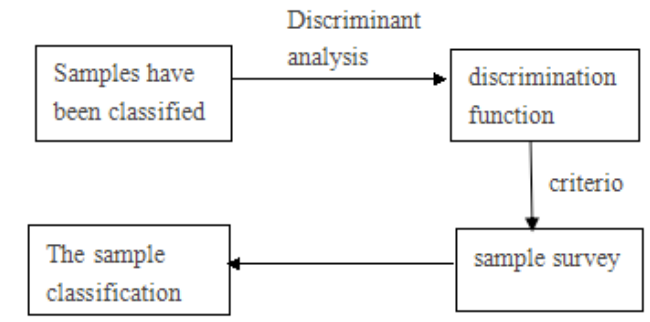

Fig. (6). The discriminant analysis step.

Discriminant analysis refers to carry out discriminant analysis of historical data, and further establish discriminant function, and make classification of observed data. Here, utilize Bayes discriminant analysis to carry out standard research on deaf-mute students' physical health development.

\subsection{Establish Discriminant Analysis Model}

Bayes discriminant analysis is a kind of method that analyzes two classes or multiple classes' data; here deaf- mute students' physical health development should accord to their genders and physical exercise items to make analysis, so use Bayes discriminant analysis is most suitable.

Under Bayes discriminant analysis discrimination criterion, established classification function form is:

$$
\left\{\begin{array}{l}
y_{1}=c_{01}+c_{11} x_{1}+c_{21} x_{2}+c_{31} x_{3}+\cdots+c_{p 1} x_{p} \\
y_{2}=c_{02}+c_{12} x_{1}+c_{22} x_{2}+c_{32} x_{3}+\cdots+c_{p 2} x_{p} \\
y_{3}=c_{03}+c_{13} x_{1}+c_{23} x_{2}+c_{33} x_{3}+\cdots+c_{p 3} x_{p} \\
\cdots \\
y_{n}=c_{0 n}+c_{1 n} x_{1}+c_{2 n} x_{2}+c_{3 n} x_{3}+\cdots+c_{p n} x_{p}
\end{array}\right.
$$

That is to establish regarding observed indicators and observed objects linear function equations, every equation corresponds to a class discriminant criterion, from which $c_{0 j}, c_{1 j}, \cdots, c_{p j}, j=1,2, \cdots, n$ is estimated parameter. After establishing discriminant functions, input one discriminant correspondingly each parameter value into above discriminant parameter, and then it can know which class the object belongs to.

According to above data, make data processing, and establish Bayes discriminant analysis classification function equation set, so that define deaf-mute students physical health standard.

\subsection{Establish Bayes Discriminant Analysis Classification Function}

Utilize SPSS software to analyze above Tables $\mathbf{3}$ and $\mathbf{4}$ data, and then it can get following classification function regarding deaf-mute students physical health standards:

$$
\begin{gathered}
y_{\text {boy }}=0.428 x_{1}+0.529 x_{2}+1.001 x_{3}+0.391 x_{4}-0.061 x_{5} \\
+0.225 x_{6}+0.467 x_{7}+0.575 x_{8}+0.624 x_{9}-52.621 \\
y_{\text {girl }}=0.353 x_{1}+0.425 x_{2}+1.031 x_{3}+0.322 x_{4}-0.054 x_{5} \\
+0.231 x_{6}+0.454 x_{7}+0.521 x_{8}+0.631 x_{9}-49.068
\end{gathered}
$$

\subsection{Improved Bayes Discriminant Analysis Classification Function}

In order to improve discrimination accuracy, firstly add one item as prior probability, it makes improvements on above Bayes discriminant analysis classification function equations. Prior probability can properly improve 
Table 4. Physical health standard (men).

\begin{tabular}{|c|c|c|c|c|c|c|c|c|c|}
\hline & Height & Weight & $\begin{array}{c}\text { Lung } \\
\text { Capacity }\end{array}$ & Sit and Reach & Grip & $\begin{array}{c}\text { Standing Long } \\
\text { Jump }\end{array}$ & Push-up & $\begin{array}{c}\text { Selection } \\
\text { Reaction Time }\end{array}$ & $\begin{array}{c}\text { Closed One } \\
\text { Leg Standing }\end{array}$ \\
\hline Standard & 168.3 & 61.2 & 2545.1 & 8.65 & 41.2 & 201.3 & 12.0 & 0.575 & 14.1 \\
\hline
\end{tabular}

Table 5. Physical health standard (women).

\begin{tabular}{|c|c|c|c|c|c|c|c|c|c|}
\hline & Height & Weight & Lung capacity & Sit and reach & Grip & $\begin{array}{c}\text { Standing long } \\
\text { jump }\end{array}$ & $\begin{array}{c}\text { 1min sit-up } \\
\text { Selection reac- } \\
\text { tion time }\end{array}$ & $\begin{array}{c}\text { Closed one leg } \\
\text { standing }\end{array}$ \\
\hline Standard & 156.7 & 53.2 & 1799.6 & 8.89 & 25.3 & 161.1 & 16.2 & 0.505 & 8.9 \\
\hline
\end{tabular}

Table 6. Comparison of deaf-mute students' likability on physical exercises.

\begin{tabular}{|c|c|c|c|c|c|}
\hline & Special Liking & Prefer & General & Didn't Like & Very Annoying \\
\hline \hline Proportion\% & $21.13 \%$ & $2.82 \%$ & $19.72 \%$ & $8.45 \%$ & $47.89 \%$ \\
\hline
\end{tabular}

discrimination accuracy, its defined criterion is according to lots of documents reports or previous a great deal of samples researches.

On the basis of prior probability, Bayes discriminant analysis classification function is converted into following form:

$$
\left\{\begin{array}{l}
y_{1}=c_{01}+c_{11} x_{1}+c_{21} x_{2}+c_{31} x_{3}+\cdots+c_{p 1} x_{p}+\ln \left(q\left(y_{1}\right)\right) \\
y_{2}=c_{02}+c_{12} x_{1}+c_{22} x_{2}+c_{32} x_{3}+\cdots+c_{p 2} x_{p}+\ln \left(q\left(y_{2}\right)\right) \\
y_{3}=c_{03}+c_{13} x_{1}+c_{23} x_{2}+c_{33} x_{3}+\cdots+c_{p 3} x_{p}+\ln \left(q\left(y_{3}\right)\right) \\
\cdots \\
y_{n}=c_{0 n}+c_{1 n} x_{1}+c_{2 n} x_{2}+c_{3 n} x_{3}+\cdots+c_{p n} x_{p}+\ln \left(q\left(y_{n}\right)\right)
\end{array}\right.
$$

According to above deaf-mute students' physical health standards status, it can define deaf-mute students' physical health standards priority probabilities are respectively $q\left(y_{\text {boy }}\right)=0.55, q\left(y_{\text {girl }}\right)=0.45$.

On the basis of considering prior probabilities, it can further get about deaf-mute students' physical health standards Bayes classification function as following:

$y_{\text {boy }}=0.428 x_{1}+0.529 x_{2}+1.001 x_{3}+0.391 x_{4}-0.061 x_{5}$

$+0.225 x_{6}+0.467 x_{7}+0.575 x_{8}+0.624 x_{9}-52.621+\ln (0.55)$

$y_{\text {girl }}=0.353 x_{1}+0.425 x_{2}+1.031 x_{3}+0.322 x_{4}-0.054 x_{5}$

$+0.231 x_{6}+0.454 x_{7}+0.521 x_{8}+0.631 x_{9}-49.068+\ln (0.45)$

That:

$$
\begin{gathered}
y_{\text {boy }}=0.428 x_{1}+0.529 x_{2}+1.001 x_{3}+0.391 x_{4}-0.061 x_{5} \\
+0.225 x_{6}+0.467 x_{7}+0.575 x_{8}+0.624 x_{9}-53.219 \\
y_{\text {girl }}=0.353 x_{1}+0.425 x_{2}+1.031 x_{3}+0.322 x_{4}-0.054 x_{5} \\
+0.231 x_{6}+0.454 x_{7}+0.521 x_{8}+0.631 x_{9}-49.867
\end{gathered}
$$

Define classification standards:
By deaf-mute students' physique researches, combine with above analysis, it can get deaf-mute people physical health all kinds of standards as following Tables $\mathbf{4}$ and $\mathbf{5}$.

Above data is different genders' deaf-mute students' physical health standard. By the standard, it is clear that when carrying out different items' physique testing; it should consider deaf-mute students' physical health. With respect to this, to research on deaf-mute students' differences in physical exercises, now carry out following statistical analysis.

\section{DEAF-MUTE STUDENTS' PHYSICAL EXERCISE HOBBIES ANALYSIS}

\subsection{Deaf-Mute Students' Likability on Physical Exercises}

Though deaf-mute students are social vulnerable groups, their physical quality, psychological quality are inferior to normal students, but to sports passion, they are not inferior to normal students. Below Table 6 and Fig. (7) are Chinese deaf-mute students' likability to physical exercise, make numerical analysis of them, and analyze results.

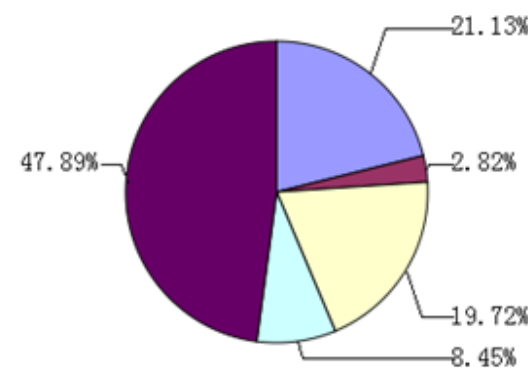

$\square$ Special likin

Prefer

$\square$ General

$\square$ Didn't like

Very annoying

Fig. (7). The deaf students love the degree of physical exercise.

By above analysis, it can get conclusions: Chinese deafmute students suffer physical quality influences, their enthusiasm on physical exercises is not high, $47.89 \%$ deafmute students are very annoying with physical exercises, which also has close relations with their psychological health to certain extent. 


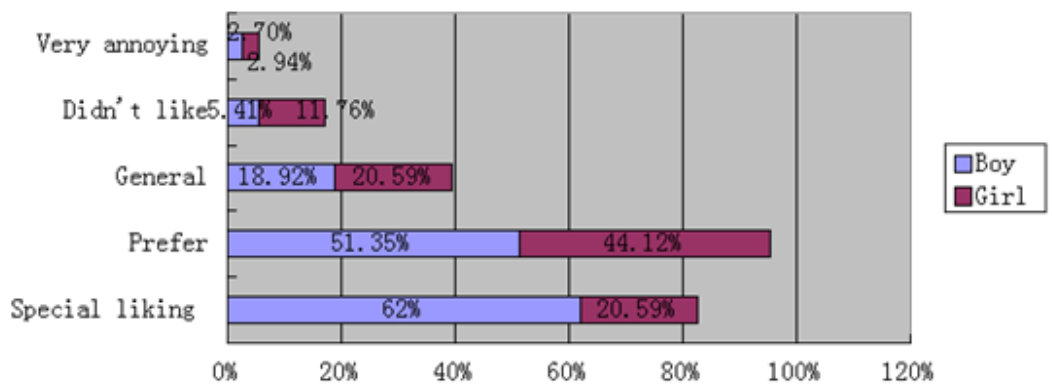

Fig. (8). Deaf students for physical exercise love degree of gender differences.

Table 7. Deaf-mute students' gender differences in physical exercises likability.

\begin{tabular}{|c|c|c|c|c|c|}
\hline Unit\% & Special Liking & Prefer & General & Didn't Like & Very Annoying \\
\hline \hline Schoolboys & $62 \%$ & $51.35 \%$ & $18.92 \%$ & $5.41 \%$ & $2.70 \%$ \\
\hline Schoolgirls & $20.59 \%$ & $44.12 \%$ & $20.59 \%$ & $11.76 \%$ & $2.94 \%$ \\
\hline
\end{tabular}

\subsection{Deaf-Mute Students Gender Differences in Physical Exercises}

Deaf-mute students, except for having differences from normal students in physical exercises, they also have obvious gender differences. Schoolboys' psychological quality is better than schoolgirls, therefore their fondness on physical exercise is higher, and schoolgirls' psychological enduring capacity is lower, they don't like participating in physical exercises type collective activities very much (Fig. 8).

By above Table 7 and Fig. (8) analysis, it can get conclusions: in deaf-mute students schoolboys, $62 \%$ students like physical exercises very much, and schoolgirls are only $20.59 \%, 44.12 \%$ schoolgirls just prefer to sports activities. It mainly because deaf-mute schoolgirls are with more inferiority complex and don't like collective activities.

\section{CONCLUSION}

The paper starts from deaf-mute students physical basic quality and physical health standard as well as deaf-mute students' physical exercise hobbies, makes research on deafmute students. Firstly, utilize normality test methods, analyze deaf-mute students physical test completion all kinds of indicators, and then get conclusions: deaf-mute students' physique compares to normal students, they have great differences, and genders differences are remarkable, when taking sports test, it should respective carry out with different physical standards.

Secondly, the paper utilizes numerical analysis and discriminant analysis method, first researches deaf-mute students' physical health standards, and on this basis, analyzes deaf-mute students' likability on sports, and then gets conclusions: when carrying out different events physical tests, different genders deaf-mute students physical health standards are different. Suffering physical quality influences, deaf-mute students enthusiasm on physical exercises is not high, most of deaf-mute students are very annoying with physical exercises, and gender difference is prominent, schoolboys preference on physical exercises are higher while schoolgirls are lower.

\section{CONFLICT OF INTEREST}

The authors confirm that this article content has no conflict of interest.

\section{ACKNOWLEDGEMENTS}

Declared none.

\section{REFERENCES}

[1] L. Yin, and H. Cai-hua, "Influence of sports self-concept and selfefficacy on sports practice of university students," J. Sports. Ad. Educ., vol. 27, no. 6, pp. 32-35, 2011.

[2] L. Jian-qiang, "Comparative research on difference between body shape and function and physical fitness of college students for different body-mass index level," J. Pla Inst. Phys. Educ., vol. 30, no. 1, pp. 125-128, 2011.

[3] L. Hao, L. Lei, L. Li-ping, L.V. Xiao-mei, and Y. Ling-wei, "The analysis and research of the comprehensive intervention measures on over-weight or obesity middle-aged groups in hebei province," J. Hebei Inst. Phys. Educ., vol. 22, no. 6, 2008.

[4] N. Jian-li, "Study of transformation of college students' exercise methods," Bull. Sport Sci. Technol., vol. 21, no. 4, pp. 85-87, 90, 2013.

[5] S. Dongzhe, and Y. Guang, "Study on physical characteristics and influencing factors of fat students with difference physical exercise,” J. Hubei Sports Sci., vol. 32, no. 3, pp. 215-217, 2013.

[6] Y. Qiu-bo, and X. Hai-xiao, "Research on the differences of spare time exercise behavior between two different body weight students," Zhejiang Sport. Sci., vol. 35, no. 5, 2013. 